\title{
Pivotal role of vascular endothelial growth factor pathway in tumor angiogenesis
}

\author{
Sang Hun Lee ${ }^{1,2}$, Dongjun Jeong ${ }^{3}$, Yong-Seok Han', Moo Jun Baek ${ }^{4}$ \\ ${ }^{1}$ Medical Science Research Institute, Soonchunhyang University Seoul Hospital, Seoul, Departments of ${ }^{2}$ Biochemistry, ${ }^{3}$ Pathology, \\ and ${ }^{4}$ Surgery, Soonchunhyang University College of Medicine, Cheonan, Korea
}

The shaping of new blood vessels is a significant event in cancer growth and metastasis. Therefore, the molecular system of cancer angiogenesis has garnered considerable interest in cancer research. The vascular endothelial growth factor (VEGF) and VEGF receptor pathway are recognized as the key regulators of the angiogenic process. Activation of the VEGF/ VEGF-receptor pathway initiates signaling cascades that promote endothelial cell growth, migration, and differentiation. Recently, VEGF was shown to play a role in the recruitment of bone marrow-derived endothelial progenitor cells to neovascularization sites. The role of VEGF in promoting tumor angiogenesis and the occurrence of human cancers has led to the rational design and development of agents that selectively target this pathway. Moreover, these anti-VEGF/VEGF receptor agents show therapeutic potential by inhibition of angiogenesis and tumor growth in preclinical models. In this review, we summarize the role of the VEGF pathway during tumor angiogenesis.

[Ann Surg Treat Res 2015;89(1):1-8]

Key Words: Angiogenesis inhibitors, Vascular endothelial growth factor receptors, Cell hypoxia, Tumor microenvironment

\section{INTRODUCTION}

The formation of new blood vessels from pre-existing vessels, known as angiogenesis, is an essential process in malignant tumor growth. In addition, this process is regulated by proangiogenic or angiostatic factors; when tumor cells are switched to the angiogenic phenotype, tumor growth and progression occur [1]. The angiogenesis regulators have been discovered owing to the increase in angiogenesis research after the early 1990s. For example, basic fibroblast growth factor (bFGF) and vascular endothelial growth factor (VEGF) are identified as positive regulators of angiogenesis. The first generation of angiogenesis inhibitors includes interferon- $\alpha$, angiostatin, and endostatin, whereas compounds such as bevacizumab, sunitinib, and erlotinib are currently used in clinical settings [2].

Tumor endothelial cells play an essential role in angiogenesis. Therefore, they have been demonstrated as suitable targets for cancer therapy from basic research and clinical applications [3]. There is substantial evidence that the proinflammatory response at the tumor stroma can be rerouted in a tumorpromoting direction by the stimulation of angiogenesis and tissue remodeling [4]. In this review, we discuss the current literature regarding the molecular mechanisms by which tumor angiogenesis is regulated.

\section{VASCULARENDOTHELIAL GROWTHFACTOR}

VEGF and VEGF receptors (VEGFRs) are recognized as components of one of the main signaling pathways in angio-
Received January 26, 2015, Reviewed February 6, 2015,

Accepted February 27, 2015

\section{Corresponding Author: Moo Jun Baek}

Department of Surgery, Soonchunhyang University College of Medicine,

31 Suncheonhyang 6-gil, Dongnam-gu, Cheonan 330-930, Korea

Tel: +82-41-570-3633, Fax: +82-41-571-0129

E-mail: ssurge@sch.ac.kr
Copyright (c) 2015, the Korean Surgical Society

(c) Annals of Surgical Treatment and Research is an Open Access Journal. All articles are distributed under the terms of the Creative Commons Attribution NonCommercial License (http://creativecommons.org/licenses/by-nc/4.0/) which permits unrestricted non-commercial use, distribution, and reproduction in any medium, provided the original work is properly cited. 
genesis [5]. The members of the VEGF family are five VEGF glycoproteins (VEGF-A, VEGF-B, VEGF-C, VEGF-D, and VEGF-E), and placental growth factors 1, 2. In particular, VEGF-A is the best-characterized member of the VEGF family. VEGF-A and its receptor VEGFR-2 are the main targets of the current antiangiogenic agents. The main targets of VEGF are endothelial cells, and VEGF is released by cancer cells to induce tumor angiogenesis [6]. The increase of VEGF is induced by platelet-derived growth factor (PDGF) B and hypoxia-inducible factor (HIF)-1 $\alpha$. In addition, it can also be secreted from the extracellular matrix (ECM) by matrix metalloproteinase- 9 to start an angiogenic switch that promotes tumor growth (Fig. 1). The decrease of VEGF expression in hepatocellular carcinomas (HCCs) occurs by disruption of c-Jun N-terminal kinase (JNK), a member of the mitogen-activated protein kinase (MAPK) family [7]. JNK regulates VEGF transcription via activator protein 1.
However, this effect may be indirect and mediated via factors such as interleukin (IL)-1 $\beta$ and oxygen tension. In epithelial cancers, E-cadherin is downregulated by an HIF-1 $\alpha$-dependent mechanism through the transcription factor Snail, therefore enhancing epithelial-mesenchymal transition [8]. VEGF elicits epithelial-mesenchymal transition via an autocrine loop [9], suggesting that it is involved in not only tumor angiogenesis but also in the early propagation of malignant cells outside the epithelial layer.

VEGFRs are key element of the ECM and contain an intracellular domain with a consensus tyrosine kinase sequence. VEGFR-1 and VEGFR-2 are mostly expressed in endothelial cells. However, VEGFR-3 was found to be mostly associated with lymphangiogenesis [10]. The VEGF family members bind to receptors with different affinities. VEGFR-1 is a receptor for VEGF-B and placental growth factor. In addition, during

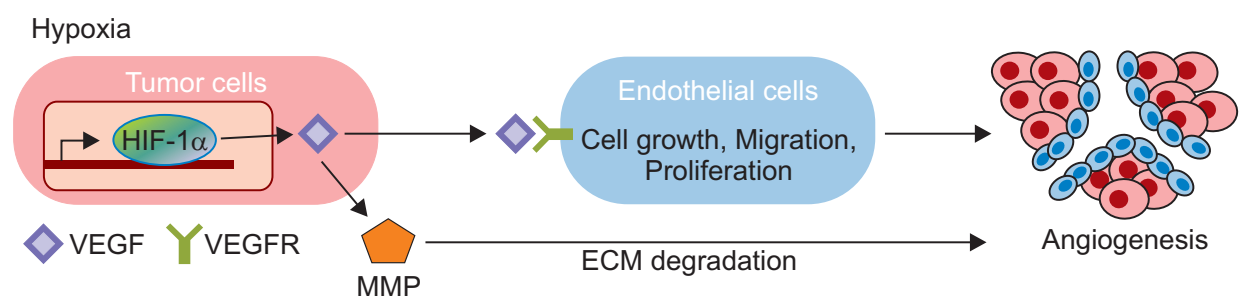

Fig. 1. VEGF/VEGFR induces tumor angiogenesis with endothelial cells. When hypoxic stress occurs in tumor cells, transcription of hypoxia-inducible factor (HIF)- $1 \alpha$ is activated, which promotes VEGF expression. The secreted VEGF binds to the VEGFR on the surface of endothelial cells, and increases MMP expression in tumor cells. As a result, tumor angiogenesis is increased leading to endothelial cell growth, proliferation, and migration. VEGF, vascular endothelial growth factor; VEGFR, VEGF receptor; MMP, matrix metalloproteinase; ECM, extracellular matrix.

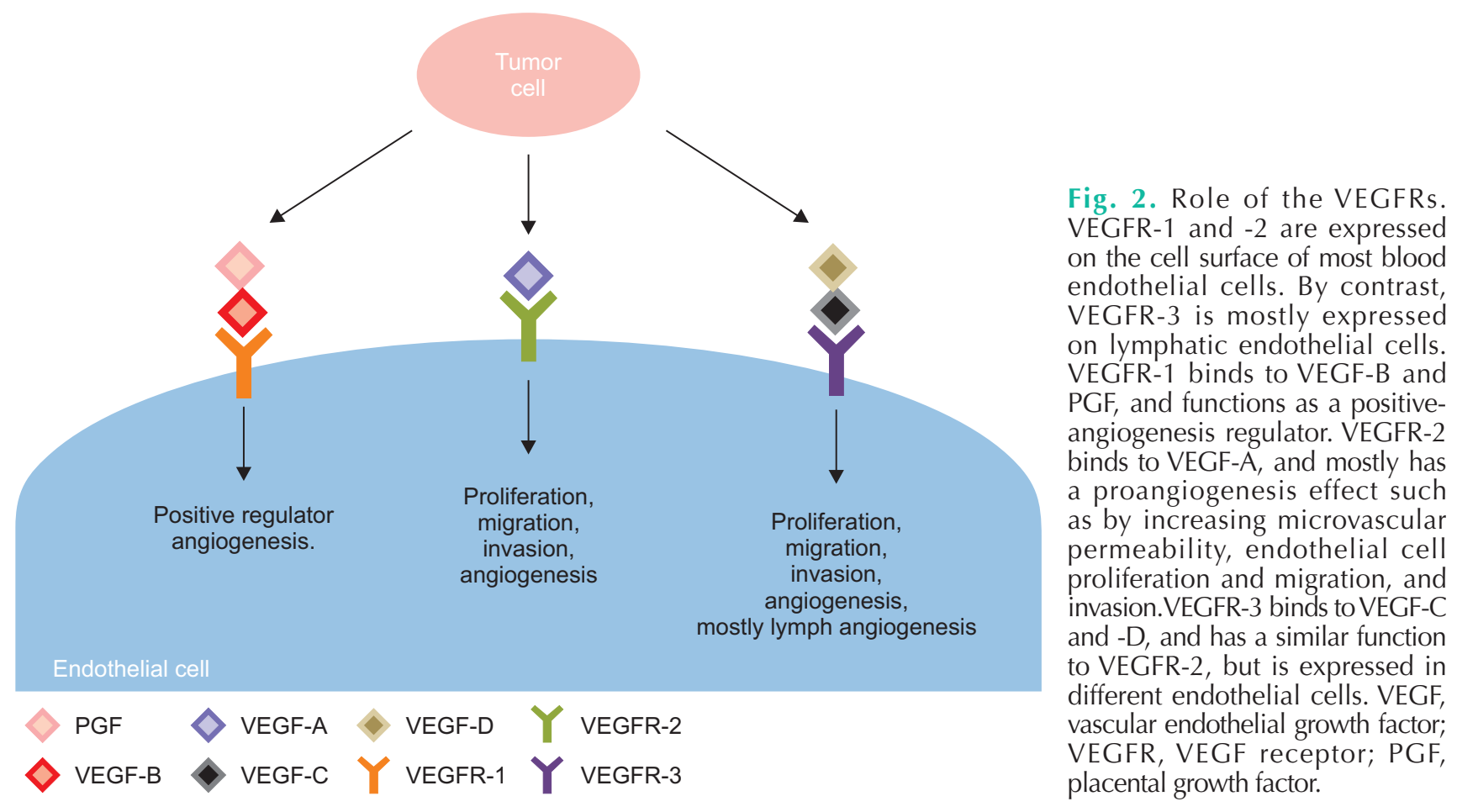


pathological conditions such as tumor occurrence, it acts as a positive regulator of angiogenesis.VEGFR-2 mostly acts as a mediator of the cellular effects of VEGF-A during angiogenesis, and is involved in microvascular permeability, endothelial cell proliferation, migration, and invasion [5]. VEGFR-3 has highest affinities to VEGF-C and VEGF-D, and induces lymphangiogenesis (Fig. 2). In addition, VEGFR-3 is similar to VEGFR-2, in contributing to angiogenesis and both are expressed on tumor blood vessels as well as on lymphatics. Neuropilins 1 and 2 serve as coreceptors for VEGF, and increase the binding affinity of ligands to VEGFRs [11]. Targeting of the tumor vasculature is an especially interesting therapeutic strategy because of the supposed genetic stability of endothelial cells [12]. Indeed, current antiangiogenic pathway agents were approved by the U.S. Food and Drug Administration (FDA). These agents that target VEGFR-2 [13] include bevacizumab, a humanized anti-VEGF-A monoclonal antibody [14], and sorafenib and sunitinib, small-molecule inhibitors. In combination with other anticancer agents, the addition of bevacizumab significantly increased the progression-free survival and median overall survival in non-small cell lung cancer (NSCLC) and colorectal cancer [15,16]. It has been demonstrated that systemic administration of sorafenib, a tyrosine kinase inhibitor targeting the VEGF and extracellularsignal reated kinase pathways, significantly increased the survival of patients with late-stage HCC [17]. However, antiangiogenic treatments targeting a single pathway, such as VEGF-A, rarely induce durable tumor responses both in mice and in patients with cancer [18], and may also favor metastasis in selected tumor models [19]. The mechanism for this acquired resistance is not well reported but may partially result from the expansion or expression of repetition changes in the maturing vasculature [20], and epigenetic mechanisms [21]. Recently, tumor resistance or recurrence after antiangiogenic therapy was found to be caused by the relapse of bone marrow-derived myeloid cells [22]. Indeed, damaging the tumor vasculature induces tumor hypoxic conditions, which in turn upregulate the expression of some myeloid cell chemoattractants that enhance the influx of myeloid cells to treated tumors [18]. The myeloid cells enhance angiogenesis by secreting angiogenic and tissue-remodeling factors [23], in addition to stimulating tumor cell intravasation, dissemination, and metastasis [24]. Therefore, identification of new antiangiogenesis targets is important and further research is needed for their discovery.

\section{REGULATORS OF VEGF AND VEGFR EXPRESSION}

\section{Hypoxia}

VEGF expression is influenced by hypoxia. Recent research has shown that HIF-1 is the key factor of the hypoxic response, and also plays an important role in the product of the von Hippel Lindau (vHL) tumor suppressor gene $[5,25,26]$. Under normoxic conditions, HIF-1 $\alpha$ is rapidly degraded by the ubiquitin-proteasome pathway; a process that is controlled by the vHL tumor suppressor gene product $[25,27]$. VEGF transcription is induced under hypoxia conditions, when vHL is mutated or absent, or when the HIF-1 $\alpha$ complex is bound to the VEGF promoter.

\section{Growth factors and cytokines}

The cytokines and growth factors are known through several studies that can control the expression of angiogenic factors in tumor cells and thereby induce angiogenesis indirectly. The importance of the epidermal growth factor receptor (EGFR, ErbB1) and HER-2/ErbB2 systems in VEGF regulation and angiogenesis has been verified in several tumor systems, including colon cancer [28], pancreatic cancer [29], gastric cancer [30], breast cancer [31,32], glioblastoma multiforme [33], NSCLC [34], and renal cell carcinoma [35]. The insulin-like growth factor I receptor (IGF-IR) is often overexpressed in human cancers, and has been associated with fatal disease and metastases [36]. Recently, research model systems have shown the significance of the activation of the IGF-IR system in arbitrating angiogenesis by upregulating VEGF expression in several types of cancers [37]. VEGF expression is possibly induced by hepatocyte growth factor via activation of mesenchymal epithelial transition factor in normal and cancer cells [38]. PDGFs were shown to induce angiogenesis via regulating the survival of endothelial cells and pericyte/vascular smooth muscle cell recruitment in vivo, and were also found to induce VEGF in several model system [39]. Dong et al. [40] recently reported the PDGF has a significant role in regulating stromal-derived VEGF-A. PDGF-AA expression was shown to promote recruitment of tumor-associated fibroblasts and VEGF production by researchers using VEGF-knockdown cancer cells. Angiogenesis and tumor growth were significantly inhibited by obstruction of paracrine PDGF receptor-alpha (PDGFR- $\alpha$ ) signaling among tumor cells and stromal fibroblasts. Therefore, these results show that PDGFR- $\alpha$ signaling is vital for the recruitment of VEGF-expressing stromal fibroblasts, and secreted VEGF of host cells is important for maintaining tumor angiogenesis.

The prostaglandins have important functions in many biological processes. In addition, particular prostaglandins were recently shown to be related to tumor angiogenesis via the upregulation of VEGF expression [41]. The function of the ratelimiting enzyme prostaglandin-endoperoxide synthase (also known as cyclooxygenase or $\mathrm{COX}$ ) is involved in the oxidative transformation of arachidonic acid into various prostaglandin compounds [42]. In the last 10 years, many studies have demonstrated a relationship between COX-2 overexpression, tumor growth, and increasing VEGF expression for angiogenesis 
in many solid tumors, including gastric [43], colon [44], prostate [45], breast [46], and pancreatic [47] cancers. Moreover, many in vivo research showed the VEGF expression by COX-2 in many cell lines [41]; however, COX-2 inhibitors do not affect VEGF expression in all tumors, indicating that this effect may be tumor-dependent.

\section{Oncogenes and tumor suppressor genes}

Generally, oncogenes have the capacity to induce proangiogenic factors and growth factors such as VEGF, and are associated with the angiogenesis system of solid tumors [48]. The tyrosine kinase pp60src is encoded by the c-Src protooncogene; it has been associated with the regulation of VEGF expression, and to enhance angiogenesis in growing tumors [49]. In addition, several factors that regulate VEGF expression are dependent on $\mathrm{c}-\mathrm{Src}-\mathrm{mediated}$ signal transduction in tumor systems [49]. Similarly, the BCR-ABL oncogene has been demonstrated to play an important role for angiogenesisdependent tumors in the molecular pathogenesis of leukemias [50]. Recent research has shown that VEGF levels were reduced in BCR-ABL-positive chronic myeloid leukemia cells by the use of STI-571 to target BCR-ABL [51]. In addition, transfection of BCR-ABL promoted expression of VEGF in mouse myeloid cells and human megakaryocytes.

Mutation in the Ras oncogene is a common genetic change observed in human cancers. In addition, the mutation of $\mathrm{H}$ - or $\mathrm{K}$ - Ras oncogenes induces VEGF expression in various cancers such as pancreatic cancer, colon cancer, and NSCLC cells [52-54]. In addition, genetic change of the mutant K-Ras allele in human colon cancer cells was related to a decrease in VEGF activity [55]. The activation of Ras or similar signaling molecules forms part of signaling cascade started by specific growth factor receptors such as EGFR [56,57], which may be one of the important signaling pathways for VEGF expression and growth factordependent angiogenesis.

p53 is a tumor suppressor gene related to the molecular pathology of many types of solid tumors. In addition, several studies have demonstrated that $\mathrm{p} 53$ plays an important role in the regulation of VEGF in tumors. Breast cancer cells inhibit transcriptional activation of the VEGF promoter via interaction between $\mathrm{p} 53$ protein and the transcription factor Sp1 [58], and this inhibition results in hypoxic induction of Src kinase. Stable transfection of wild-type p53 resulted in decreased VEGF expression in colon and endometrial cancer cells [59,60]. Several studies have also demonstrated that increased HIF1 activity in cancer tissues led to increases in VEGF levels via genetic changes of tumor suppressor genes such as vHL, p53, and Phosphatase and tensin homolog $[61,62]$.

\section{VEGFR EXPRESSION IN TUMOR CELLS}

The role of VEGF in tumor angiogenesis was established via stimulation of VEGFRs on the tumor endothelium. However, there is increasing evidence that VEGF may have an additional role in cancer via stimulation of VEGFRs in tumor cells.

Several studies have demonstrated the presence of VEGFRs in liquid and solid tumor cells, such as NSCLC, melanoma, prostate cancer, leukemia, mesothelioma, and breast cancer [50,63-67]. The relevance of this expression pattern is still under investigation. These results must also be construed with discretion, because many of these studies have using immunohistochemical staining, which can lead to high false positive rates. Nonetheless, it could be hypothesized that diverse VEGF ligands support tumor growth, not only by inducing angiogenesis but also by direct action via VEGFRs expression by tumor cells. In addition, because most solid tumors and various hematologic tumors have the ability to express VEGF, expression of VEGFRs by tumor cells involves the latent role of VEGF/VEGFR autocrine signaling in these tumors. Corresponding with this hypothesis, recent research has demonstrated that for specific leukemias, VEGFRs may be vital for tumor cell growth by enhancing a VEGF/VEGFR autocrine signal, which induces tumor growth arrest and apoptosis when interrupted. For example, Dias et al. [68] have demonstrated that functional VEGF/VEGFR-2 autocrine signals exist in subsets of human leukemias and support in vivo leukemic cell survival and migration [50]. Treatment of mice bearing transplanted human leukemia cells with a function-blocking VEGFR-2 antibody has been shown to result in decreased tumor growth and survival. Price et al. [67] have shown that VEGFR-1 is expressed in various breast cancer cell lines and that stimulation of breast cancer cells with VEGF induced invasion and signaling in vitro, suggesting a possible autocrine pathway that leads to increased tumorigenesis. Recently, VEGFR-1 expression has been detected in many colon, breast, and pancreatic cancer cell lines [67,69]. Ex vivo studies have also shown that VEGFR-1 activation by VEGF-A or VEGF-B induces increased cell invasion and migration, as well as phenotypic changes associated with activation of the MAPK pathway in tumor cells [70]. Thus, VEGF appears to enhance cell growth in human tumors by direct action with VEGFRs through an endothelial cell-independent pathway, and therefore may serve as a useful target for cancer therapy.

\section{SUMMARY OF THERAPEUTIC STRATEGIES TO INHIBIT THE VEGF PATHWAY}

As an important regulator of tumor angiogenesis, there has been increasing interest in and efforts made to utilize the capacity of the VEGF pathway for therapeutic strategies 
in oncology. Thus, strategies focused on antiangiogenesis therapy via inhibition of the VEGF pathway are currently in preclinical and clinical development. Some of the current antiVEGF strategies include development of antibodies to VEGF or VEGFRs, tyrosine kinase inhibitors of VEGFRs, and soluble VEGFR/VEGFR hybrids [71-75].

Many anti-VEGF agents are progressing toward testing in clinical trials. Among the anti-VEGF antibodies, bevacizumab (in combination with chemotherapy) is the first of these agents to be permitted for use in tumor therapy by the FDA.

The use of neutralizing antibodies to VEGF was one of the earliest strategies used to inhibit VEGF activity. In preclinical research, the anti-VEGF monoclonal antibody of mice was found to inhibit angiogenesis and growth of transplanted human tumors [73]. Preclinical data of anti-VEGFR-2 antibodies have shown successful inhibition of the VEGF-induced signaling pathway, antiangiogenesis, and decreased primary and metastatic growth in variety tumor systems $[76,77]$. The other main approach to obstruct VEGF-mediated angiogenesis is the use of small-molecule inhibitors of VEGFR tyrosine kinase activity. The function of some tyrosine kinase inhibitors selectively inhibit VEGFR-2 but also show activity on other VEGFRs and other diverse tyrosine kinase receptors, including the PDGFR- $\alpha$, PDGFR- $\beta$, bFGF receptor, EGFR family members, c-kit, and Flt3.

A successful strategy that can indirectly regulate the VEGF pathway would result in antiangiogenic effects such as inhibition of diverse regulators of VEGF expression, and production of EGFR, HER-2, COX-2, or HIF-1 $\alpha$. However, each of the angiogenic factors produced, such as VEGF, is associated with multiple regulatory factors and intracellular signaling pathways. Thus, targeting one pathway through the inhibition may not induce complete inhibition of angiogenesis or VEGF, which may still be activated by many other pathways. In this regard, drug resistance is an important consideration in the development of VEGF-targeted therapies, and is need of mention. One of the advantages of antiangiogenic agents is their ability to evade acquired resistance to therapy and drugs; the reader is referred to several excellent reviews on this topic [78]. This hypothesis is based on the supposition of genetically stable host vasculature in the targets of anti-VEGF therapy. Nonetheless, tumors can be exceptionally heterogeneous with respect to their dependence on microenvironmental factors. Therefore, other tumors may be intrinsically resistant to certain environmental conditions. For example, several tumors may be highly sensitive to hypoxia conditions and therefore more reactive in inhibiting VEGF. To date, there is a lack of evidence of the acquired resistance for VEGF-targeted agents. However, several preclinical studies have shown the prevention of relapse tumor growth after an evident initial phase of inhibition during chronic VEGF/VEGFR blockade [79]. One possible mechanism underlying this relapse growth is the compensatory upregulation of other proangiogenic factors (or down-regulation of antiangiogenic factors) by cancer or stromal cells, which results in the remodeling and increased efficiency of the tumor vasculature. Recently, the results of preclinical research have provided support for this hypothesis [20]. Long-term anti-VEGF treatment after Wilms' tumor transplantation has been shown to significantly increase the tumor vessel radius with active proliferation of vascular mural cells and stromal cell recruitment. Furthermore, increased tumor perfusion and relapse tumor growth accompanied these morphological changes in tumor vessels. Additional research of the resistance mechanisms against VEGF-targeted agents is warranted in the future.

\section{CONCLUSIONS}

The complex molecular pathways that regulate tumor angiogenesis are major targets for pharmacological development, owing to their important roles in the promotion and regulation in the growth and development of cancers. Tumor cells are genetically unstable, which is considered the main cause of the failure of systemic chemotherapies. Endothelial cells in the tumor stroma are considered to be genetically stable, and it is believed that these cells will not become drug-resistant in response to antivascular therapy. However, recent research has demonstrated that endothelial cells are aneuploid and tumor markers [80]. Signals from some other stromal cell types have been demonstrated to regulate tumor growth and their responsiveness to therapies in diverse models, raising the possibility that drugs interfering with these pathways could supply additional therapeutic strategies. Future research focused on altering the tumor microenvironment involved in tumor angiogenesis may lead to new therapeutic applications via regulation of the critical mediators of tumor growth.

\section{CONFLICTS OF INTEREST}

No potential conflict of interest relevant to this article was reported.

\section{ACKNOWLEDGEMENTS}

This study was supported by a National Research Foundation (NRF) grant funded by the Korean government (MEST) (20110009610) and the Soonchunhyang University Research Fund. The funders had no role in study design, data collection or analysis, the decision to publish, or preparation of the manuscript. 
1. Folkman J, Kalluri R. Cancer without disease. Nature 2004:427:787.

2. Kerbel R, Folkman J. Clinical translation of angiogenesis inhibitors. Nat Rev Cancer 2002;2:727-39.

3. Mueller MM, Fusenig NE. Friends or foes - bipolar effects of the tumour stroma in cancer. Nat Rev Cancer 2004:4:839-49.

4. Budhu A, Forgues M, Ye QH, Jia HL, He $\mathrm{P}$, Zanetti KA, et al. Prediction of venous metastases, recurrence, and prognosis in hepatocellular carcinoma based on a unique immune response signature of the liver microenvironment. Cancer Cell 2006;10:99-111.

5. Ferrara N, Gerber HP, LeCouter J. The biology of VEGF and its receptors. Nat Med 2003;9:669-76.

6. Grothey A, Galanis E. Targeting angiogenesis: progress with anti-VEGF treatment with large molecules. Nat Rev Clin Oncol 2009;6:507-18.

7. Sakurai T, Maeda S, Chang L, Karin M. Loss of hepatic NF-kappa B activity enhances chemical hepatocarcinogenesis through sustained c-Jun $\mathrm{N}$-terminal kinase 1 activation. Proc Natl Acad Sci U S A 2006; 103:10544-51.

8. Peinado H, Olmeda D, Cano A. Snail, Zeb and bHLH factors in tumour progression: an alliance against the epithelial phenotype? Nat Rev Cancer 2007;7:415-28.

9. Gonzalez-Moreno O, Lecanda J, Green JE, Segura V, Catena R, Serrano D, et al. VEGF elicits epithelial-mesenchymal transition (EMT) in prostate intraepithelial neoplasia (PIN)-like cells via an autocrine loop. Exp Cell Res 2010;316:554-67.

10. Grothey A, Ellis LM. Targeting angiogenesis driven by vascular endothelial growth factors using antibody-based therapies. Cancer J 2008;14:170-7.

11. Hicklin DJ, Ellis LM. Role of the vascular endothelial growth factor pathway in tumor growth and angiogenesis. J Clin Oncol 2005;23:1011-27.

12. Folkman J. What is the evidence that tumors are angiogenesis dependent? J
Natl Cancer Inst 1990;82:4-6.

13. Escudier B, Eisen T, Stadler WM, Szczylik C, Oudard S, Siebels M, et al. Sorafenib in advanced clear-cell renal-cell carcinoma. N Engl J Med 2007;356:125-34.

14. Ferrara N, Hillan KJ, Gerber HP, Novotny W. Discovery and development of bevacizumab, an anti-VEGF antibody for treating cancer. Nat Rev Drug Discov 2004; 3:391-400.

15. Hurwitz H, Fehrenbacher L, Novotny W, Cartwright T, Hainsworth J, Heim W, et al. Bevacizumab plus irinotecan, fluorouracil, and leucovorin for metastatic colorectal cancer. N Engl J Med 2004:350:2335-42.

16. Sandler A, Gray R, Perry MC, Brahmer J, Schiller JH, Dowlati A, et al. Paclitaxelcarboplatin alone or with bevacizumab for non-small-cell lung cancer. N Engl J Med 2006;355:2542-50.

17. Llovet JM, Ricci S, Mazzaferro V, Hilgard P, Gane E, Blanc JF, et al. Sorafenib in advanced hepatocellular carcinoma. N Engl J Med 2008;359:378-90.

18. Bergers G, Hanahan D. Modes of resistance to anti-angiogenic therapy. Nat Rev Cancer 2008;8:592-603.

19. Ebos JM, Lee CR, Cruz-Munoz W, Bjarnason GA, Christensen JG, Kerbel RS. Accelerated metastasis after short-term treatment with a potent inhibitor of tumor angiogenesis. Cancer Cell 2009; 15:232-9.

20. Huang J, Soffer SZ, Kim ES, McCrudden KW, Huang J, New T, et al. Vascular remodeling marks tumors that recur during chronic suppression of angiogenesis. Mol Cancer Res 2004:2:36-42.

21. Glasspool RM, Teodoridis JM, Brown R. Epigenetics as a mechanism driving polygenic clinical drug resistance. $\mathrm{Br} \mathrm{J}$ Cancer 2006;94:1087-92.

22. Shojaei F, Wu X, Malik AK, Zhong C, Baldwin ME, Schanz S, et al. Tumor refractoriness to anti-VEGF treatment is mediated by $\mathrm{CD} 11 \mathrm{~b}+\mathrm{Gr} 1+$ myeloid cells. Nat Biotechnol 2007;25:911-20.

23. De Palma M, Venneri MA, Galli R, Sergi
Sergi L, Politi LS, Sampaolesi M, et al. Tie2 identifies a hematopoietic lineage of proangiogenic monocytes required for tumor vessel formation and a mesenchymal population of pericyte progenitors. Cancer Cell 2005;8:211-26.

24. DeNardo DG, Barreto JB, Andreu P, Vasquez L, Tawfik D, Kolhatkar N, et al. CD4(+) T cells regulate pulmonary metastasis of mammary carcinomas by enhancing protumor properties of macrophages. Cancer Cell 2009;16:91-102.

25. Iliopoulos O, Levy AP, Jiang C, Kaelin WG Jr, Goldberg MA. Negative regulation of hypoxia-inducible genes by the von Hippel-Lindau protein. Proc Natl Acad Sci U S A 1996;93:10595-9.

26. Gordan JD, Simon MC. Hypoxia-inducible factors: central regulators of the tumor phenotype. Curr Opin Genet Dev 2007; 17:71-7.

27. Maxwell PH, Ratcliffe PJ. Oxygen sensors and angiogenesis. Semin Cell Dev Biol 2002;13:29-37.

28. Ciardiello F, Bianco R, Damiano V, Fontanini G, Caputo R, Pomatico G, et al. Antiangiogenic and antitumor activity of anti-epidermal growth factor receptor C225 monoclonal antibody in combination with vascular endothelial growth factor antisense oligonucleotide in human GEO colon cancer cells. Clin Cancer Res 2000;6:3739-47.

29. Parikh AA, Liu WB, Fan F, Stoeltzing O, Reinmuth N, Bruns CJ, et al. Expression and regulation of the novel vascular endothelial growth factor receptor neuropilin-1 by epidermal growth factor in human pancreatic carcinoma. Cancer 2003:98:720-9.

30. Akagi M, Kawaguchi M, Liu W, McCarty MF, Takeda A, Fan F, et al. Induction of neuropilin-1 and vascular endothelial growth factor by epidermal growth factor in human gastric cancer cells. Br J Cancer 2003;88:796-802.

31. Kumar R, Yarmand-Bagheri R. The role of HER2 in angiogenesis. Semin Oncol 
2001:28(5 Suppl 16):27-32.

32. Yang W, Klos K, Yang Y, Smith TL, Shi D, Yu D. ErbB2 overexpression correlates with increased expression of vascular endothelial growth factors A, C, and D in human breast carcinoma. Cancer 2002; 94:2855-61.

33. Eller JL, Longo SL, Hicklin DJ, Canute GW. Activity of anti-epidermal growth factor receptor monoclonal antibody C225 against glioblastoma multiforme. Neurosurgery 2002:51:1005-13.

34. Muguruma H, Yano S, Sone S. Non-small cell lung cancer: 1) Molecular-target therapy. Nihon Naika Gakkai Zasshi 2003; 92:1284-90

35. Kedar D, Baker CH, Killion JJ, Dinney CP, Fidler IJ. Blockade of the epidermal growth factor receptor signaling inhibits angiogenesis leading to regression of human renal cell carcinoma growing orthotopically in nude mice. Clin Cancer Res 2002;8:3592-600.

36. Reinmuth N, Fan F, Liu W, Parikh AA, Stoeltzing $\mathrm{O}$, Jung YD, et al. Impact of insulin-like growth factor receptor-I function on angiogenesis, growth, and metastasis of colon cancer. Lab Invest 2002; 82:1377-89.

37. Jenkins PJ, Bustin SA. Evidence for a link between IGF-I and cancer. Eur J Endocrinol 2004:151 Suppl 1:S17-22.

38. Eder JP, Vande Woude GF, Boerner SA, LoRusso PM. Novel therapeutic inhibitors of the c-Met signaling pathway in cancer. Clin Cancer Res 2009;15:2207-14.

39. Kotsuji-Maruyama T, Imakado S, Kawachi Y, Otsuka F. PDGF-BB induces MAP kinase phosphorylation and VEGF expression in neurofibroma-derived cultured cells from patients with neurofibromatosis 1. J Dermatol 2002:29:713-7.

40. Dong J, Grunstein J, Tejada M, Peale F, Frantz G, Liang WC, et al. VEGF-null cells require PDGFR alpha signaling-mediated stromal fibroblast recruitment for tumorigenesis. EMBO J 2004:23:2800-10.

41. Gately S. The contributions of cyclooxygenase-2 to tumor angiogenesis. Cancer Metastasis Rev 2000;19:19-27.

42. Brash AR. Arachidonic acid as a bioactive molecule. J Clin Invest 2001;107:1339-45.

43. Joo YE, Rew JS, Seo YH, Choi SK, Kim YJ, Park CS, et al. Cyclooxygenase-2 overexpression correlates with vascular endothelial growth factor expression and tumor angiogenesis in gastric cancer. J Clin Gastroenterol 2003:37:28-33.

44. Yao M, Kargman S, Lam EC, Kelly CR, Zheng Y, Luk P, et al. Inhibition of cyclooxygenase-2 by rofecoxib attenuates the growth and metastatic potential of colorectal carcinoma in mice. Cancer Res 2003;63:586-92.

45. Toomey DP, Murphy JF, Conlon KC. COX-2, VEGF and tumour angiogenesis. Surgeon 2009;7:174-80.

46. Costa C, Soares R, Reis-Filho JS, Leitao D, Amendoeira I, Schmitt FC. Cyclo-oxygenase 2 expression is associated with angiogenesis and lymph node metastasis in human breast cancer. J Clin Pathol 2002:55:429-34.

47. Eibl G, Bruemmer D, Okada Y, Duffy JP, Law RE, Reber HA, et al. PGE(2) is generated by specific COX-2 activity and increases VEGF production in COX-2-expressing human pancreatic cancer cells. Biochem Biophys Res Commun 2003; 306:887-97.

48. Rak J, Yu JL, Kerbel RS, Coomber BL. What do oncogenic mutations have to do with angiogenesis/vascular dependence of tumors? Cancer Res 2002;62:1931-4.

49. Summy JM, Trevino JG, Baker CH, Gallick GE. c-Src regulates constitutive and EGF-mediated VEGF expression in pancreatic tumor cells through activation of phosphatidyl inositol-3 kinase and p38 MAPK. Pancreas 2005;31:263-74.

50. Dias S, Hattori K, Heissig B, Zhu Z, Wu Y, Witte L, et al. Inhibition of both paracrine and autocrine VEGF/ VEGFR-2 signaling pathways is essential to induce long-term remission of xenotransplanted human leukemias. Proc Natl Acad Sci U S A 2001; 98:10857-62.

51. Ebos JM, Tran J, Master Z, Dumont D, Melo JV, Buchdunger E, et al. Imatinib mesylate (STI-571) reduces Bcr-Abl-mediated vascular endothelial growth factor secretion in chronic myelogenous leukemia. Mol
Cancer Res 2002;1:89-95.

52. Konishi T, Huang CL, Adachi M, Taki T, Inufusa $\mathrm{H}$, Kodama $\mathrm{K}$, et al. The K-ras gene regulates vascular endothelial growth factor gene expression in non-small cell lung cancers. Int J Oncol 2000;16:501-11.

53. Ikeda N, Nakajima Y, Sho M, Adachi M, Huang CL, Iki K, et al. The association of K-ras gene mutation and vascular endothelial growth factor gene expression in pancreatic carcinoma. Cancer 2001; 92:488-99.

54. Zhang X, Gaspard JP, Chung DC. Regulation of vascular endothelial growth factor by the Wnt and K-ras pathways in colonic neoplasia. Cancer Res 2001;61:6050-4.

55. Rak J, Mitsuhashi Y, Bayko L, Filmus J, Shirasawa S, Sasazuki T, et al. Mutant ras oncogenes upregulate VEGF/VPF expression: implications for induction and inhibition of tumor angiogenesis. Cancer Res 1995:55:4575-80.

56. Maity A, Pore N, Lee J, Solomon D, O'Rourke DM. Epidermal growth factor receptor transcriptionally up-regulates vascular endothelial growth factor expression in human glioblastoma cells via a pathway involving phosphatidylinositol 3'-kinase and distinct from that induced by hypoxia. Cancer Res 2000;60:5879-86.

57. Casanova ML, Larcher F, Casanova B, Murillas R, Fernandez-Acenero MJ, Villanueva C, et al. A critical role for ras-mediated, epidermal growth factor receptor-dependent angiogenesis in mouse skin carcinogenesis. Cancer Res 2002;62:3402-7.

58. Pal S, Datta K, Mukhopadhyay D. Central role of p53 on regulation of vascular permeability factor/vascular endothelial growth factor (VPF/VEGF) expression in mammary carcinoma. Cancer Res 2001; 61:6952-7.

59. Fujisawa T, Watanabe J, Kamata Y, Hamano M, Hata H, Kuramoto H. Effect of p53 gene transfection on vascular endothelial growth factor expression in endometrial cancer cells. Exp Mol Pathol 2003;74:27681.

60. Bouvet M, Ellis LM, Nishizaki M, Fujiwara T, Liu W, Bucana CD, et al. Adenovirusmediated wild-type p53 gene transfer 
down-regulates vascular endothelial growth factor expression and inhibits angiogenesis in human colon cancer. Cancer Res 1998:58:2288-92.

61. Maxwell PH, Wiesener MS, Chang GW, Clifford SC, Vaux EC, Cockman ME, et al. The tumour suppressor protein VHL targets hypoxia-inducible factors for oxygen-dependent proteolysis. Nature 1999:399:271-5.

62. Zundel W, Schindler C, Haas-Kogan D, Koong A, Kaper F, Chen E, et al. Loss of PTEN facilitates HIF-1-mediated gene expression. Genes Dev 2000;14:391-6.

63. Bellamy WT. Expression of vascular endothelial growth factor and its receptors in multiple myeloma and other hematopoietic malignancies. Semin Oncol 2001;28:551-9.

64. Kajita T, Ohta Y, Kimura K, Tamura M, Tanaka Y, Tsunezuka Y, et al. The expression of vascular endothelial growth factor $C$ and its receptors in non-small cell lung cancer. Br J Cancer 2001;85:25560.

65. Bairey O, Boycov O, Kaganovsky E, Zimra Y, Shaklai M, Rabizadeh E. All three receptors for vascular endothelial growth factor (VEGF) are expressed on B-chronic lymphocytic leukemia (CLL) cells. Leuk Res 2004:28:243-8.

66. Jennbacken K, Vallbo C, Wang W, Damber JE. Expression of vascular endothelial growth factor C (VEGF-C) and VEGF receptor-3 in human prostate cancer is associated with regional lymph node metastasis. Prostate 2005:65:110-6.

67. Price DJ, Miralem T, Jiang S, Steinberg R, Avraham $\mathrm{H}$. Role of vascular endothelial growth factor in the stimulation of cellular invasion and signaling of breast cancer cells. Cell Growth Differ 2001;12:129-35.

68. Dias S, Hattori K, Zhu Z, Heissig B, Choy M, Lane W, et al. Autocrine stimulation of VEGFR-2 activates human leukemic cell growth and migration. J Clin Invest 2000;106:511-21.

69. Wu Y, Zhong Z, Li H, Huber J, Bassi R, Hooper A, et al. A fully human monoclonal antibody against VEGFR-1 inhibits growth of human breast cancers [abstract \#3005]. Proc Am Assoc Cancer Res 2004: 45.

70. Fan F, Wey JS, McCarty MF, Belcheva A, Liu W, Bauer TW, et al. Expression and function of vascular endothelial growth factor receptor-1 on human colorectal cancer cells. Oncogene 2005;24:2647-53.

71. Kamba T, McDonald DM. Mechanisms of adverse effects of anti-VEGF therapy for cancer. Br J Cancer 2007;96:1788-95.

72. Ferrara N. VEGF as a therapeutic target in cancer. Oncology 2005;69 Suppl 3:11-6.

73. Gerber HP, Kowalski J, Sherman D, Eberhard DA, Ferrara N. Complete inhibition of rhabdomyosarcoma xenograft growth and neovascularization requires blockade of both tumor and host vascular endothelial growth factor. Cancer Res 2000;60:6253-8.
74. Arora A, Scholar EM. Role of tyrosine kinase inhibitors in cancer therapy. J Pharmacol Exp Ther 2005:315:971-9.

75. Shojaei F. Anti-angiogenesis therapy in cancer: current challenges and future perspectives. Cancer Lett 2012;320:130-7.

76. Bruns CJ, Shrader M, Harbison MT, Portera C, Solorzano CC, Jauch KW, et al. Effect of the vascular endothelial growth factor receptor-2 antibody DC101 plus gemcitabine on growth, metastasis and angiogenesis of human pancreatic cancer growing orthotopically in nude mice. Int J Cancer 2002;102:101-8.

77. Shaheen RM, Ahmad SA, Liu W, Reinmuth $\mathrm{N}$, Jung YD, Tseng WW, et al. Inhibited growth of colon cancer carcinomatosis by antibodies to vascular endothelial and epidermal growth factor receptors. Br J Cancer 2001;85:584-9.

78. Kerbel RS. Clinical trials of antiangiogenic drugs: opportunities, problems, and assessment of initial results. J Clin Oncol 2001;19(18 Suppl):45S-51S.

79. Klement G, Baruchel S, Rak J, Man S, Clark K, Hicklin DJ, et al. Continuous lowdose therapy with vinblastine and VEGF receptor-2 antibody induces sustained tumor regression without overt toxicity. J Clin Invest 2000;105:R15-24.

80. Streubel B, Chott A, Huber D, Exner M, Jager U, Wagner O, et al. Lymphomaspecific genetic aberrations in microvascular endothelial cells in B-cell lymphomas. N Engl J Med 2004:351:250-9. 